\title{
Avaliação sensorial de sorvetes à base de xilitol
}

\author{
Sensory evaluation of ice creams prepared with xylitol \\ Maria Cristina Antun MAIA ${ }^{1 \star}$, Ana Paula Gomes Lopes Kuhner GALVÃO², \\ Regina Célia DELLA MODESTA³ ${ }^{3}$ Nei PEREIRA JÚNIOR ${ }^{1}$
}

\begin{abstract}
Resumo
O presente trabalho objetivou relacionar o poder adoçante de solução de xilitol e sacarose, procurando saber se existe diferença de doçura entre sorvetes de nata, morango e chocolate adicionados destes dois adoçantes, em diferentes concentrações, assim como verificar a qualidade sensorial do produto quanto a aparência, cor, aroma, consistência e sabor. Houve diferenças significativas $(\mathrm{p}<0,05)$ em todas as formulações, exceto entre as formulações de morango nas concentrações de $100 \%$ sacarose versus $50 \%$ xilitol. Quanto à qualidade dos sorvetes, pode-se observar que o sorvete de nata e suas 3 concentrações de adoçantes foram as formulações que apresentaram maiores diferenças de qualidade, pois dos 5 atributos avaliados, obteve-se diferença significativa $(\mathrm{p}<0,05)$ para 4 deles (aparência, cor, consistência e sabor). O sorvete de morango foi o mais uniforme em questão de qualidade, pois apresentou diferença significativa $(\mathrm{p}<0,05)$ apenas para a consistência. $\mathrm{O}$ sorvete de chocolate esteve numa posição intermediária, pois apresentou diferença significativa $(\mathrm{p}<0,05)$ para a consistência e o sabor.

Palavras-chave: qualidade sensorial; sorvete; xilitol.
\end{abstract}

\begin{abstract}
The aim of this study was to compare the sweetening power of xylitol and sucrose solutions, verifying differences in sweetness among cream, strawberry and chocolate flavoured ice creams sweetened with these two sweeteners, and also determining the sensory quality of the products with respect to appearance, colour, aroma, consistency and flavour. There were significant differences $(\mathrm{p}<0.05)$ among all the formulations except between the strawberry formulations made with $100 \%$ sucrose and $50 \%$ xylitol. With respect to quality, the cream flavoured ice creams presented the greatest differences in quality among the three concentrations of sweeteners, since of the five attributes evaluated, significant differences $(\mathrm{p}<0.05)$ were obtained for four of them (appearance, colour, consistency and flavour). The strawberry ice creams were the most uniform with respect to quality, only presenting significant differences $(\mathrm{p}<0.05)$ for consistency. The chocolate ice creams were intermediate, presenting significant differences $(\mathrm{p}<0.05)$ for consistency and flavour.
\end{abstract}

Keywords: sensory quality; ice cream; xylitol.

\section{Introdução}

O sorvete é um produto que agrada aos mais variados paladares, de todas as faixas etárias e de qualquer classe social. Sorvetes são alimentos refrescantes que combinam muito bem com o clima tropical do país, onde existe uma variada gama de ingredientes que podem ser usados para enriquecer e diversificar ainda mais as receitas de sorvetes, ingredientes estes que vão das frutas mais exóticas às sementes dos mais diversos tipos (ARBUCKLE, 1986).

Segundo a Agência Nacional de Vigilância Sanitária, sorvete ou gelado comestível é "um produto alimentício obtido a partir de uma emulsão de gordura e proteínas, com ou sem adição de outros ingredientes e substâncias, ou de uma mistura de água, açúcares e outros ingredientes e substâncias que tenham sido submetidas ao congelamento, em condições tais que garantam a conservação do produto no estado congelado ou parcialmente congelado, durante a armazenagem, o transporte e a entrega ao consumo" (BRASIL, 2005).

Do ponto de vista nutricional, o sorvete é considerado um alimento completo e de alto valor nutritivo, pois fornece proteínas, carboidratos, lipídeos, vitaminas $\mathrm{A}, \mathrm{B}_{1}, \mathrm{~B}_{2}, \mathrm{~B}_{6}, \mathrm{C}, \mathrm{D}, \mathrm{E}$ e K, cálcio, fósforo e outros minerais (ARBUCKLE, 1986).

Independente da classificação, o sorvete é, devido às suas propriedades nutricionais, uma excelente fonte de energia, e por isto um alimento especialmente desejável para crianças em fase de crescimento e para pessoas que precisam recuperar peso. Pelo mesmo motivo, deve ter sua ingestão controlada ou evitada na dieta de pessoas que necessitam reduzir peso ou mesmo as que não querem ganhá-lo (ARBUCKLE, 1986).

O xilitol (penta-hidroxi-pentano) é classificado como um edulcorante nutritivo ou calórico, denominação esta dada se-

\footnotetext{
Recebido para publicação em 27/9/2006

Aceito para publicação em 18/12/2007 (001866)

${ }^{1}$ Departamento de Engenharia Bioquímica, Escola de Química, Universidade Federal do Rio de Janeiro - UFRJ, Centro de Tecnologia, Bloco E, sala 203,

Cidade Universitária, CEP 21949-900, Ilha do Fundão, Brasil, E-mail: antun@eq.ufrj.br

2 Instituto de Química, Universidade Federal do Rio de Janeiro - UFRJ, Brasil

${ }^{3}$ Embrapa Agroindústria de Alimentos, Centro Nacional de Pesquisa de Tecnologia Agroindústrial e de Alimentos - CTAA

${ }^{*}$ A quem a correspondência deve ser enviada
} 
gundo o FDA para qualquer edulcorante que possua mais de $2 \%$ do valor calórico de sacarose por unidade equivalente de capacidade adoçante. Seu valor calórico é de 2,4 Kcal.g ${ }^{-1}$ (BRASIL, 2001; MARSHALL; GOFF, 2003; NABORS, 2003) e o poder adoçante geralmente é considerado igual ao da sacarose (CÂNDIDO; CAMPOS, 1996; O’DONNELL, 1996). Sendo um poliól ou açúcar álcool, se diferencia de outros sacarídeos por ter sofrido uma redução do grupo carbonílico (cetona ou aldeído) de açúcar a álcool, e posterior transformação da estrutura cíclica a linear. Estas conversões conferem aos polióis propriedades importantes e particularmente interessantes para a indústria de alimentos, tais como: não sofrer reações de escurecimento tipo Maillard; possuir maior estabilidade química; maior resistência à cristalização; maior afinidade por água e menor susceptibilidade à fermentação. $\mathrm{O}$ xilitol é muito utilizado em alimentos como agente de "corpo", e em conjunto com outros edulcorantes pode atenuar o gosto residual destes ou apresentar efeitos sinérgicos de edulcoração (aumento do poder adoçante) quando em misturas contendo outros edulcorantes (CÂNDIDO; CAMPOS, 1996).

Outra característica interessante do xilitol é o seu valor negativo de calor de dissolução $\left(-34,8\right.$ cal.g $\left.{ }^{-1}\right)$, o que lhe confere um agradável efeito refrescante. Apresenta solubilidade em água próxima à da sacarose $\left(195 \mathrm{~g} .100 \mathrm{~g}^{-1}\right.$ água a $\left.20^{\circ} \mathrm{C}\right)$ e é excelente agente redutor de atividade de água $\left(\mathrm{a}_{\mathrm{w}}\right)$, devido à capacidade de suas hidroxilas se ligarem à água, o que pode conferir uma maior conservação do produto (CÂNDIDO; CAMPOS, 1996; MARSHALL; GOFF, 2003; NABORS, 2003).

O xilitol pode ainda atuar como antioxidante, umectante, estabilizante, crioprotetor e redutor de ponto de congelamento (CÂNDIDO; CAMPOS, 1996; O’DONNELL, 1996).

O interesse pelo estudo e desenvolvimento de novos produtos com características de prebióticos ou probióticos tem crescido muito nos últimos anos, porque se sabe hoje que a flora normal bacteriana exerce uma função fisiológica importante na prevenção de patologias do intestino, particularmente a constipação, as colites, a diarréia e o câncer de cólon (SILVA, 1999).

Os prebióticos são predominantemente carboidratos que não são digeríveis ou que sofrem incompleta degradação pelas enzimas digestivas do corpo humano e, ao alcançarem a porção do colón, são fermentados pela flora intestinal, sendo esta utilizada no metabolismo de um número limitado de bactérias intestinais. Exemplos de prebióticos são os oligossacarídeos específicos (frutooligossacarídeos, xilooligossacarídeos, isomaltooligossacarídeos, galactooligossacarídeos, etc.), a pectina, a lactose, a lactulose, o lactitol, a inulina, a rafinose, o sorbitol e o xilitol (SCHAAFSMA, 1997).

A percepção da presença do adoçante na formulação tornase um problema menor quando comparada aos benefícios que este agrega ao alimento, não sendo, portanto, um fator limitante ao seu uso. No caso do xilitol, que tem seu metabolismo independente de insulina, valor calórico reduzido e propriedades anticariogênicas comprovadas, seu emprego se justificaria em formulações destinadas a diabéticos, obesos e pessoas preocupadas em manter a saúde oral.
O presente trabalho objetivou relacionar o poder adoçante entre solução de xilitol e de sacarose em formulações de sorvetes, procurando saber se existem diferenças significativas de doçura entre formulações de diferentes sabores (nata, morango e chocolate) contendo estes dois adoçantes, e verificar a qualidade sensorial dos sorvetes quanto a aparência, cor, aroma, consistência e sabor.

\section{Material e métodos}

\subsection{Estudo sensorial preliminar com soluções de sacarose e xilitol}

Para saber se a substituição de sacarose por xilitol poderia ser feita sem causar alteração no sabor e, portanto, sem que fosse notada pelo provador, foi realizado um estudo preliminar para relacionar o poder adoçante entre xilitol e sacarose, e saber se existiam diferenças estatisticamente significativas de poder adoçante entre soluções destes dois adoçantes. Foi realizado o teste triangular entre as soluções de sacarose e xilitol, método eficiente e indicado para detectar se existe diferença sensorial entre duas amostras como um todo.

As soluções foram preparadas, em água mineral, com sacarose comercial (açúcar refinado) e xilitol cristalino, em grau alimentício. Com base em testes sensoriais prévios, as concentrações usadas foram de 1, 2,5 e 5\% $\left(\mathrm{p} \cdot \mathrm{v}^{-1}\right)$.

As amostras foram servidas em copos plásticos brancos descartáveis com capacidade para $50 \mathrm{~mL}$, codificados por três dígitos aleatórios, apresentadas em 6 posições diferentes e balanceadas com 7 repetições aleatorizadas, totalizando 42 provas para cada concentração testada (DELLA MODESTA, 1994). Os resultados de acertos obtidos para cada concentração foram comparados segundo Roessler et al. (1978).

\subsection{Elaboração do sorvete}

\section{Formulação}

Foram elaboradas três formulações de sorvetes com $100 \%$ de sacarose, $50 \%$ de xilitol e $50 \%$ de sacarose (denominada 50\% xilitol) e 100\% xilitol. Estas três formulações foram ainda elaboradas em três diferentes sabores: nata, morango e chocolate.

O sorvete foi preparado na planta de produção de uma sorveteria artesanal, por processo descontínuo, em bateladas de 20 litros usando a formulação mostrada no Tabela 1. Os ingredientes foram adicionados gradualmente, segundo o procedimento a seguir: gordura liquefeita, $2 / 3$ da água, homogeneização por 3 minutos, adição de adoçante, leite, estabilizante e o restante da água à temperatura ambiente, homogeneização por 3 minutos, adição do emulsificante e homogeneização por 5 minutos e, por último, adição do pó saborizante e homogeneização por mais 3 minutos. A mistura foi homogeneizada em liquidificador industrial. O processamento térmico ocorreu nas seguintes condições: aquecimento da calda a $75^{\circ} \mathrm{C}$ por 15 minutos e posterior resfriamento até atingir $4{ }^{\circ} \mathrm{C}$. A mistura foi homogeneizada e maturada a $4^{\circ} \mathrm{C}$ por 2 horas, e em segui- 
da congelada em uma produtora horizontal por 8 minutos e saindo à temperatura de $-6^{\circ} \mathrm{C}$. $\mathrm{O}$ produto foi empacotado em caixa de papelão revestida de plástico, coberto por um filme plástico e armazenado em câmara de endurecimento a $-25^{\circ} \mathrm{C}$ por 1 semana até ser transferido para um freezer horizontal a $-18{ }^{\circ} \mathrm{C}$, onde permaneceu até o fim dos experimentos.

\subsection{Análises sensoriais}

Os sorvetes foram mantidos em freezer a $-18^{\circ} \mathrm{C}$ e servidos assim que retirados deste, em copos plásticos brancos descartáveis com capacidade para $50 \mathrm{~mL}$ e codificados por três dígitos aleatórios. O provador limpava o palato com água mineral à temperatura ambiente.

\section{Teste triangular de sorvetes}

Para saber se a substituição de sacarose por xilitol em formulações de sorvetes poderia ser feita sem causar alteração no sabor e, portanto, sem que fosse notada pelo provador, foi realizado o teste triangular para saber se existiam diferenças estatisticamente significativas de doçura entre as formulações de sorvetes contendo estes dois adoçantes.

As amostras foram apresentadas nas seguintes combinações, para os três sabores: $100 \%$ sacarose contra $50 \%$ xilitol; $100 \%$ sacarose contra $100 \%$ xilitol e $50 \%$ xilitol contra $100 \%$ xilitol, em posições diferentes e balanceadas, com repetições aleatorizadas, totalizando 36 provas para cada combinação (DELLA MODESTA, 1994).

Os resultados foram analisados segundo Roessler et al. (1978).

\section{Avaliação da qualidade com escala estruturada}

Com o objetivo de verificar a qualidade sensorial dos sorvetes, foi realizada a avaliação da qualidade sensorial das 9 formulações. Os atributos estabelecidos foram: aparência, cor, aroma, consistência e sabor.

As amostras foram apresentadas duas a duas, nas seguintes combinações, para os três sabores: $100 \%$ sacarose contra $50 \%$ xilitol; $100 \%$ sacarose contra $100 \%$ xilitol e $50 \%$ xilitol contra

Tabela 1. Formulação dos sorvetes de nata, morango e chocolate, nas concentrações de 100\% sacarose, 50\% xilitol e 100\% xilitol.

\begin{tabular}{lrrc}
\hline \multicolumn{1}{c}{ Ingredientes } & $\begin{array}{c}100 \% \\
\text { sacarose }\end{array}$ & $\begin{array}{c}50 \% \\
\text { xilitol }\end{array}$ & $\begin{array}{r}100 \% \\
\text { xilitol }\end{array}$ \\
\hline Água & $8000 \mathrm{~mL}$ & $8000 \mathrm{~mL}$ & $8000 \mathrm{~mL}$ \\
Leite em pó desnatado & $1440 \mathrm{~g}$ & $1440 \mathrm{~g}$ & $1440 \mathrm{~g}$ \\
Açúcar refinado & $2240 \mathrm{~g}$ & $1120 \mathrm{~g}$ & - \\
Xilitol & - & $1120 \mathrm{~g}$ & $2240 \mathrm{~g}$ \\
Gordura vegetal hidrogenada & $1000 \mathrm{~g}$ & $1000 \mathrm{~g}$ & $1000 \mathrm{~g}$ \\
Emulsificante & $120 \mathrm{~g}$ & $120 \mathrm{~g}$ & $120 \mathrm{~g}$ \\
Estabilizante & $120 \mathrm{~g}$ & $120 \mathrm{~g}$ & $120 \mathrm{~g}$ \\
Aroma de nata em pó & $120 \mathrm{~g}$ & $120 \mathrm{~g}$ & $120 \mathrm{~g}$ \\
Aroma de morango em pó & $120 \mathrm{~g}$ & $120 \mathrm{~g}$ & $120 \mathrm{~g}$ \\
Aroma de chocolate em pó & $570 \mathrm{~g}$ & $570 \mathrm{~g}$ & $570 \mathrm{~g}$ \\
\hline
\end{tabular}

${ }^{\star}$ Quantidades usadas em separado, por cada sabor de sorvete.
100\% xilitol, em posições diferentes e balanceadas, com repetições aleatorizadas, totalizando 40 provas para cada combinação (DELLA MODESTA, 1994).

O método sensorial usado foi a avaliação dos atributos, e a unidade de medida para cada atributo foi o grau atribuído pelo provador numa escala de 1 a 5 , sendo que 1 correspondeu à pior qualidade e 5 à melhor qualidade, conforme mostrado na Figura 1.

Os dados foram avaliados através de análise de variância, e as médias comparadas através do teste de Tukey, ao nível de $5 \%$ de significância.

\section{Resultados e discussão}

\subsection{Estudo sensorial de soluções de xilitol}

Os resultados obtidos com o teste triangular, para a comparação das soluções de sacarose e xilitol, em diversas concentrações estão expressos na Tabela 2.

Os resultados mostraram que somente na concentração de $1 \%$, os provadores não detectaram diferenças entre as amostras. Nas demais concentrações, foram encontradas diferenças significativas ao nível de $5 \%$ de probabilidade, indicando que nestas concentrações os provadores conseguiram detectar diferença sensorial entre as soluções de sacarose e xilitol. Estes resultados, todavia, não inviabilizam seu uso em formulações alimentícias, uma vez que o sabor do xilitol é mascarado pelos outros componentes da formulação e, portanto, menos percebido do que em solução.

\subsection{Teste triangular de sorvetes}

O teste triangular teve o objetivo de detectar alguma diferença sensorial com relação à doçura, porém na medida em que os provadores foram sendo submetidos aos testes, outros atributos foram usados para detectar diferenças entres as diversas formulações. É natural que isto ocorra, pois o fundamento do teste preconiza que não seja revelada ao provador a natureza da diferença que está sendo testada.

Como foi detectada uma variação da percepção de diferença entre os sabores, que não estava somente ligada à doçura, as formulações foram submetidas ao Teste de Qualidade para detectar claramente quais as diferenças que estavam sendo percebidas pelos provadores. Os resultados da Tabela 3 mostraram haver diferenças significativas $(p<0,05)$ em todas as formulações, exceto entre as formulações de morango, nas concentrações de $100 \%$ sacarose e $50 \%$ xilitol.

Tabela 2. Total de testes e de acertos para soluções de sacarose e xilitol.

\begin{tabular}{lcc}
\hline \multicolumn{1}{c}{ Concentração das soluções } & $\begin{array}{c}\mathrm{N}^{\circ} \text { de } \\
\text { testes }\end{array}$ & $\begin{array}{c}\mathrm{N}^{\circ} \text { de acertos } \\
\text { obtidos }\end{array}$ \\
\hline 1\% sacarose $\times 1 \%$ de xilitol & 42 & $17^{\text {ns }}$ \\
2,5\% de sacarose $\times$ 2,5\% de xilitol & 42 & $24^{*}$ \\
$5 \%$ de sacarose $\times$ 5\% de xilitol & 42 & $30^{*}$ \\
\hline ns: não significativo, segundo Roessler et al. $(1978) ;$ e $^{*}(\mathrm{p}<0,05)$, segundo \\
Roessler et al. (1978).
\end{tabular}


Teste de qualidade - escala estruturada

Nome:

Data:

Por favor, prove as amostras da esquerda para a direita e utilizando a escala de 1 a 5,

atribua um grau para cada um dos atributos abaixo, marcando-o com um circulo:

\begin{tabular}{|c|c|c|c|c|c|c|c|c|c|c|}
\hline \multicolumn{6}{|c|}{ Amostra } & \multicolumn{5}{|c|}{ Amostra } \\
\hline Aparência & 1 & 2 & 3 & 4 & 5 & 1 & 2 & 3 & 4 & 5 \\
\hline Sabor & 1 & 2 & 3 & 4 & 5 & 1 & 2 & 3 & 4 & 5 \\
\hline Cor & 1 & 2 & 3 & 4 & 5 & 1 & 2 & 3 & 4 & 5 \\
\hline Aroma & 1 & 2 & 3 & 4 & 5 & 1 & 2 & 3 & 4 & 5 \\
\hline Textura & 1 & 2 & 3 & 4 & 5 & 1 & 2 & 3 & 4 & 5 \\
\hline
\end{tabular}

Comentários:

Figura 1. Ficha resposta do teste de qualidade.

Tabela 3. Total de testes e de acertos das formulações de sorvetes.

\begin{tabular}{|c|c|c|c|}
\hline \multicolumn{2}{|c|}{ Formulação } & \multirow{2}{*}{$\begin{array}{c}\text { Total de testes } \\
36\end{array}$} & \multirow{2}{*}{$\begin{array}{c}\begin{array}{c}\mathrm{N}^{\circ} \text { de acertos } \\
\text { obtidos }\end{array} \\
22^{\star}\end{array}$} \\
\hline \multirow[t]{6}{*}{ Nata } & $100 \%$ sacarose & & \\
\hline & $50 \%$ xilitol & & \\
\hline & $100 \%$ sacarose & 36 & $30^{*}$ \\
\hline & 100\% xilitol & & \\
\hline & $50 \%$ xilitol & 36 & $34^{*}$ \\
\hline & 100\% xilitol & & \\
\hline \multirow[t]{6}{*}{ Morango } & $100 \%$ sacarose & 36 & $14^{\mathrm{ns}}$ \\
\hline & $50 \%$ xilitol & & \\
\hline & $100 \%$ sacarose & 36 & $26^{*}$ \\
\hline & 100\% xilitol & & \\
\hline & $50 \%$ xilitol & 36 & $19^{*}$ \\
\hline & $100 \%$ xilitol & & \\
\hline \multirow[t]{6}{*}{ Chocolate } & $100 \%$ sacarose & 36 & $19^{*}$ \\
\hline & $50 \%$ xilitol & & \\
\hline & $100 \%$ sacarose & 36 & $28^{*}$ \\
\hline & $100 \%$ xilitol & & \\
\hline & $50 \%$ xilitol & 36 & $23^{*}$ \\
\hline & $100 \%$ xilitol & & \\
\hline
\end{tabular}

ns: não significativo, segundo Roessler et al. (1978); $\mathrm{e}^{*}(\mathrm{p}<0,05)$, segundo Roessler et al. (1978).

Este resultado indicou que o sabor de morango aliado à substituição de metade da quantidade de sacarose por xilitol foi a formulação mais equilibrada até o momento para ser usada sem problemas de percepção sensorial.

\subsection{Teste de qualidade com escala estruturada}

O teste de qualidade com escala estruturada e avaliação de características e atributos foi usado para identificar onde estavam as diferenças detectadas pelos provadores no teste triangular de sorvetes. Através de graus, os provadores puderam avaliar os atributos de aparência, cor, aroma, consistência e sabor das 9 formulações de sorvetes, e os resultados se encontram nas Tabelas 4, 5 e 6.
Tabela 4. Médias dos atributos sensoriais de sorvete de nata.

\begin{tabular}{lccccc}
\hline \multicolumn{1}{c}{ Formulação } & Aparência & Cor & Aroma & Consistência & Sabor \\
\hline $100 \%$ sacarose & $4,5^{\mathrm{a}}$ & $4,5^{\mathrm{a}}$ & 4,2 & $4,3^{\mathrm{a}}$ & $4,1^{\mathrm{a}}$ \\
$50 \%$ xilitol & $3,6^{\mathrm{b}}$ & $3,6^{\mathrm{b}}$ & 4,0 & $3,9^{\mathrm{b}}$ & $3,9^{\mathrm{a}}$ \\
$100 \%$ xilitol & $3,9^{\mathrm{b}}$ & $4,4^{\mathrm{a}}$ & 3,8 & $2,9^{\mathrm{c}}$ & $3,3^{\mathrm{b}}$ \\
$\mathrm{F}_{\text {amostra }}$ & $18,49^{*}$ & $25,33^{*}$ & $2,66^{\text {ns }}$ & $38,88^{*}$ & $12,28^{*}$ \\
\hline${ }_{\text {ns: não significativo; }}^{*}(\mathrm{p}<0,05) ;$ e Médias com letras diferentes na coluna diferem entre si
\end{tabular}

$(\mathrm{p}<0,05)$ pelo teste de Tukey.

Tabela 5. Médias dos atributos sensoriais de sorvete de morango.

\begin{tabular}{lccccc}
\hline \multicolumn{1}{c}{ Formulação } & Aparência & Cor & Aroma & Consistência & Sabor \\
\hline $100 \%$ sacarose & 4,4 & 4,4 & 4,0 & $4,1^{\mathrm{a}}$ & 3,9 \\
$50 \%$ xilitol & 4,2 & 4,2 & 3,8 & $3,5^{\mathrm{b}}$ & 3,7 \\
$100 \%$ xilitol & 4,2 & 4,7 & 4,0 & $3,9^{\mathrm{b}}$ & 3,8 \\
$\mathrm{~F}_{\text {amostra }}$ & $1,01^{\mathrm{ns}}$ & $2,26^{\mathrm{ns}}$ & $1,15^{\mathrm{ns}}$ & $11,79^{*}$ & $1,51^{\mathrm{ns}}$ \\
\hline
\end{tabular}

ns: não significativo; ${ }^{*}(p<0,05)$; e Médias com letras diferentes na coluna diferem entre si $(\mathrm{p}<0,05)$ pelo teste de Tukey.

Tabela 6. Médias dos atributos sensoriais de sorvete de chocolate.

\begin{tabular}{lccccc}
\hline \multicolumn{1}{c}{ Formulação } & Aparência & Cor & Aroma & Consistência & Sabor \\
\hline $100 \%$ sacarose & 4,2 & 4,2 & 4,2 & $4,2^{\mathrm{a}}$ & $4,3^{\mathrm{a}}$ \\
$50 \%$ xilitol & 4,3 & 4,3 & 4,1 & $4,3^{\mathrm{a}}$ & $3,8^{\mathrm{ab}}$ \\
$100 \%$ xilitol & 4,0 & 4,2 & 4,1 & $3,3^{\mathrm{b}}$ & $3,8^{\mathrm{b}}$ \\
$\mathrm{F}_{\text {amostra }}$ & $1,77^{\mathrm{ns}}$ & $0,21^{\mathrm{ns}}$ & $0,65^{\mathrm{ns}}$ & $26,14^{*}$ & $5,08^{*}$ \\
\hline
\end{tabular}

ns: não significativo; ${ }^{*}(\mathrm{p}<0,05)$; e Médias com letras diferentes na coluna diferem entre si $(\mathrm{p}<0,05)$ pelo teste de Tukey.

Para o atributo aparência, somente o sorvete de nata apresentou diferenças significativas $(\mathrm{p}<0,05)$ entre as três concentrações de adoçantes, onde se observou que o sorvete com $100 \%$ de sacarose teve qualidade significativamente melhor que os sorvetes de 50 e $100 \%$ xilitol. Os demais sabores não apresentaram diferenças de qualidade significativas $(\mathrm{p}>0,05)$.

Com relação ao atributo cor, apenas o sorvete de nata apresentou diferença significativa $(\mathrm{p}<0,05)$ entre as três concentrações de adoçantes, onde se observou que o sorvete com $50 \%$ xilitol diferiu dos sorvetes de $100 \%$ sacarose e $100 \%$ xilitol. 
Os demais sabores não apresentaram diferenças significativas $(\mathrm{p}>0,05)$ quanto à qualidade da cor.

$\mathrm{O}$ atributo aroma não apresentou diferenças significativas ( $p>0,05)$ em nenhuma das 9 formulações, ou seja, a presença ou não de xilitol foi indiferente para este atributo.

O atributo consistência apresentou diferenças significativas $(\mathrm{p}<0,05)$ de qualidade nos três sabores e entre as três concentrações de adoçantes; para o sorvete de nata as três concentrações diferiram entre si $(\mathrm{p}<0,05)$ com relação à qualidade, sendo que os sorvetes de nata e de morango com $100 \%$ sacarose se mostraram com qualidade superior; e o sorvete de chocolate teve a concentração de $100 \%$ xilitol diferindo das demais, mostrando uma qualidade inferior em relação às demais concentrações.

$\mathrm{O}$ atributo sabor não apresentou diferenças significativas $(\mathrm{p}>0,05)$ de qualidade para o sorvete de morango, porém os sorvetes de nata e chocolate apresentaram diferenças significativas $(\mathrm{p}<0,05)$. O sorvete de nata apresentou diferença significativa de qualidade para a formulação, contendo 100\% de xilitol; os sorvetes com $100 \%$ sacarose e $50 \%$ xilitol não diferiram entre si. Para o sorvete de chocolate, as concentrações de 100\% sacarose e $50 \%$ xilitol diferiram da concentração de $100 \%$ xilitol, que por sua vez, junto com a concentração de $50 \%$ xilitol, diferiu do sorvete com $100 \%$ sacarose.

Os resultados mostraram que o sorvete de nata e suas 3 concentrações de adoçantes foram as formulações que apresentaram maiores diferenças de qualidade, pois dos 5 atributos avaliados obteve-se diferença significativa $(\mathrm{p}<0,05)$ para 4 deles (aparência, cor, consistência e sabor). O sorvete de morango, nas três concentrações de adoçantes avaliadas, foi o mais uniforme em questão de qualidade, pois apresentou diferença significativa $(\mathrm{p}<0,05)$ apenas para o atributo consistência. $\mathrm{O}$ sorvete de chocolate estaria numa posição intermediária, pois apresentou diferença significativa $(\mathrm{p}<0,05)$ para os atributos consistência e sabor.

Estes resultados estão em consonância com os comentários deixados pelos provadores nas fichas de avaliação. Foi relatado que o sorvete de nata com $50 \%$ xilitol apresentava um derretimento mais rápido, com aspecto mais soft (como se fosse uma mousse) e uma certa arenosidade quando comparado ao sorvete de nata com 100\% sacarose; além disto ele apresentava uma cor branca mais escura (mais acinzentada) quando comparado aos demais. Para o sorvete de nata com $100 \%$ xilitol foi relatada a presença de excessiva arenosidade e fácil derretimento quando comparado tanto com o $100 \%$ sacarose, quanto com o $50 \%$ xilitol. Para o sorvete de morango, os relatos se resumiram na presença de arenosidade na concentração de 50 e 100\% xilitol e excessivo sabor doce para as 3 concentrações. O sorvete de chocolate com $100 \%$ sacarose foi considerado muito semelhante ao sorvete com $50 \%$ xilitol, sendo difícil a detecção de diferenças; o sorvete chocolate com $100 \%$ xilitol foi considerado muito doce e arenoso. Todos os sorvetes contendo 100\% sacarose foram considerados doces e com boa consistência (firmes e sem arenosidade).

\section{Conclusões}

Como era esperado, as propriedades da sacarose e do xilitol influenciaram na qualidade de formulações de sorvetes e, conseqüentemente, nos resultados sensoriais.

$\mathrm{Na}$ concentração de $1 \%$ não foi possível detectar diferença $(p>0,05)$ entre as soluções de sacarose e xilitol. Nas demais concentrações (2,5 e 5,0\%) foram encontradas diferenças significativas $(\mathrm{p}<0,05)$ entre as soluções de sacarose e de xilitol.

No caso dos sorvetes, houve diferenças significativas $(p<0,05)$ em todas as formulações, exceto entre as formulações de morango nas concentrações de $100 \%$ sacarose versus $50 \%$ xilitol. Isto indicou que o sabor de morango aliado à substituição de metade da quantidade de sacarose por xilitol foi a formulação mais equilibrada até o momento para ser usada sem problemas de percepção sensorial.

Quanto à qualidade dos sorvetes, pode-se observar que o sorvete de nata e suas 3 concentrações de adoçantes foram as formulações que apresentaram maiores diferenças de qualidade, pois dos 5 atributos avaliados, obteve-se diferença significativa $(\mathrm{p}<0,05)$ para 4 deles (aparência, cor, consistência e sabor). Os sorvetes de morango foram os mais uniformes em questão de qualidade, pois apresentaram diferença significativa $(\mathrm{p}<0,05)$ apenas para a consistência. $\mathrm{O}$ sorvete de chocolate esteve numa posição intermediária, pois apresentou diferença significativa $(\mathrm{p}<0,05)$ para a consistência e o sabor.

Os estudos sensoriais mostram que é viável o desenvolvimento de novas formulações de sorvete contendo xilitol, porém alguns aspectos sensoriais ainda precisam ser mais bem trabalhados para que a preferência e a aceitabilidade por parte dos consumidores aumentem ainda mais, superando desta forma as suas expectativas.

\section{Agradecimentos}

Os autores agradecem à Fundação de Amparo à Pesquisa do Estado do Rio de Janeiro - FAPERJ.

\section{Referências bibliográficas}

ARBUCKLE, W. S. Ice Cream. 4. ed. AVI Publishing Company, Inc., Westport, Connecticut, 1986.

BRASIL (2001) Ministério da Saúde. Agência Nacional de Vigilância Sanitária. Resolução - RDC n. ${ }^{\circ}$ 40, 21 mar. 2001. Regulamento Técnico para Rotulagem Nutricional Obrigatória de alimentos e bebidas embalados. Diário Oficial da União de 13/02/2002, Seção 1. Disponível em http://www.anvisa.gov.br/legis/resol/40_01rdc. htm

BRASIL (2005) Ministério da Saúde. Agência Nacional de Vigilância Sanitária. Resolução n. ${ }^{\circ}$ 266, 22 set. 2005. Regulamento Técnico para Gelados Comestíveis e Preparados para Gelados Comestíveis. Diário Oficial da União de 23 set. 2005, Seção 1. Disponível em: $<$ http://e-legis.anvisa.gov.br/leisref/public/showAct. php?id $=18825 \&$ word $=>$.

CÂNDIDO, L. M. B.; CAMPOS, A. M. Alimentos para fins Especiais: Dietéticos. Livraria Varella, São Paulo, 1996.

DELLA MODESTA, R. C. Manual de Análise Sensorial de Alimentos e Bebidas. EMBRAPA/CTAA, Rio de Janeiro, 1994. 
MARSHALL, R. T.; GOFF, D. Formulating and Manufacturing Ice Cream and Other Frozen Desserts. Food Technology, v. 57, n. 5, p. 32-44, 2003.

NABORS, L. O. Sweet choices: sugar replacements for foods and beverages. Food Technology, v. 56, n. 7, p. 28-34, 2003.

O'DONNELL, C. D. Polyols as formulation problem solvers. Prepared Food, v. 165, n. 2, p. 39-41, 1996.

ROESSLER, E. B. et al. Expanded statistical tables for estimating significance in paired-preference, paired difference, duo-trio and triangle tests. Journal of Food Science, v. 43, n. 3, p. 940-943, 1978.
SCHAAFSMA, G. The Western Diet, With A Special Focus On Dairy Products. Danone Chairs Monographs, Edited by Institut Danone, 1997, 124 p.

SILVA, N. Relação entre dieta e saúde - o conceito de alimentos funcionais. Engenharia de Alimentos, RPA Editorial, São Paulo, v. 26, p. 40-42, set/out, 1999.

YAMAZAKI, J. Informações básicas sobre a pasteurização. Sorveteria Confeitaria Brasileira, Ano XXIV, Publitec do Brasil Ltda. 2002. 